2017-08-16

\title{
Aeolian sediment fingerprinting using a Bayesian mixing model
}

\author{
Gholami, H
}

http://hdl.handle.net/10026.1/9893

10.1002/esp.4189

Earth Surface Processes and Landforms

Wiley

All content in PEARL is protected by copyright law. Author manuscripts are made available in accordance with publisher policies. Please cite only the published version using the details provided on the item record or document. In the absence of an open licence (e.g. Creative Commons), permissions for further reuse of content should be sought from the publisher or author. 


\section{Earth Surface}

Processes and Landforms

\section{Aeolian sediment fingerprinting using a Bayesian mixing model}

\begin{tabular}{|r|l|}
\hline Journal: & Earth Surface Processes and Landforms \\
\hline Manuscript ID & ESP-17-0002.R1 \\
\hline Wiley - Manuscript type: & Research Article \\
\hline Date Submitted by the Author: & n/a \\
\hline Complete List of Authors: & $\begin{array}{l}\text { Gholami, Hamid; University of Hormozgan, Department of Range and } \\
\text { Watershed Management } \\
\text { Telfer, Matt; Plymouth University, School of Geography, Earth and } \\
\text { Environmental Sciences } \\
\text { Blake, William; Plymouth University, SoGEES } \\
\text { Fathabadi, Abolhassan; University of Gonbad-e-Kavoos, Department of } \\
\text { Range and Watershed Management }\end{array}$ \\
\hline Keywords: & $\begin{array}{l}\text { Aeolian sediment, Sand provenance, Markov Chain Monte Carlo, } \\
\text { Fingerprinting, Dune }\end{array}$ \\
\hline
\end{tabular}

SCHOLARONE ${ }^{\mathrm{m}}$

Manuscripts 


\section{Aeolian sediment fingerprinting using a Bayesian mixing model}

2

3 Hamid Gholami ${ }^{a^{*}}$, Matt W. Telfer ${ }^{b^{*}}$, William H. Blake ${ }^{b}$ and Abolhassan Fathabadi ${ }^{c}$

4 a Department of Range and Watershed Management, University of Hormozgan,

5 Bandar-Abbas, Hormozgan, Iran.

6 b School of Geography, Earth and Environmental Sciences, Plymouth University,

7 Plymouth, Devon, PL4 8AA, UK.

8 c Department of Range and Watershed Management, University of Gonbad-e-

9 Kavoos, Gonbad-e-Kavoos, Golestan, Iran.

10 * Correspondence to:

11 Hamid Gholami, Department of Range and Watershed Management, University of 12 Hormozgan, Bandar-Abbas, Hormozgan, Iran. E-mail address:

13 hgholami@hormozgan.ac.ir. Tel: +98 9370865077.

14 and

15 Matt Telfer, School of Geography, Earth and Environmental Science, Plymouth 16 University, Plymouth, Devon, PL4 8AA, UK. E-mail address: 17 matt.telfer@plymouth.ac.uk. Tel: +44 1752585570.

19 Abstract

20 Identifying sand provenance in depositional aeolian environments (e.g. dunefields)

21 can elucidate sediment pathways and fluxes, and inform potential land management

22 strategies where windblown sand and dust is a hazard to health and infrastructure. 
23 However, the complexity of these pathways typically makes this a challenging 24 proposition, and uncertainties on the composition of mixed-source sediments are 25 often not reported. This study demonstrates that a quantitative fingerprinting method 26 within the Bayesian Markov Chain Monte Carlo (MCMC) framework offers great 27 potential for exploring the provenance and uncertainties associated with aeolian 28 sands.

29 Eight samples were taken from dunes of the small $\left(\sim 58 \mathrm{~km}^{2}\right)$ Ashkzar erg, central 30 Iran, and forty-nine from three distinct potential sediment sources from the 31 surrounding area. These were analyzed for 61 tracers including 53 geochemical 32 elements (trace, major and rare earth elements (REE)) and 8 REE ratios. Kruskal33 Wallis $\mathrm{H}$-tests and stepwise discriminant function analysis (DFA) allowed the 34 identification of an optimum composite fingerprint based on six tracers $\left(\mathrm{Rb}, \mathrm{Sr},{ }^{87} \mathrm{Sr}\right.$, $35(\mathrm{La} / \mathrm{Yb})_{\mathrm{n}}, \mathrm{Ga}$ and $\left.\delta \mathrm{Ce}\right)$, and a Bayesian mixing model was applied to derive the source apportionment estimates within an uncertainty framework.

37 There is substantial variation in the uncertainties in the fingerprinting results, with some samples yielding clear discrimination of components, and some with less clear fingerprints. Quaternary terraces and fans contribute the largest component to the 40 dunes, but they are also the most extensive surrounding unit; clay flats and marls, 41 however, contribute out of proportion to their small outcrop extent. The successful 42 application of these methods to aeolian sediment deposits demonstrates their 43 potential for providing quantitative estimates of aeolian sediment provenances in 44 other mixed-source arid settings, and may prove especially beneficial where 45 sediment is derived from multiple sources, or where other methods of provenance 46 (e.g. detrital zircon $\mathrm{U}-\mathrm{Pb}$ dating) are not possible due to mineralogical constraints. 
1

2

3

4

5

6

7

8

9

10

11

12

13

14

15

16

17

18

19

20

21

22

23

24

25

26

27

28

29

30

31

32

33

34

35

36

37

38

39

40

41

42

43

44

45

46

47

48

49

50

51

52

53

54

55

56

57

58

59

60

47 Key words: Sand provenance; Aeolian sediment; Markov Chain Monte Carlo;

48 Fingerprinting; uncertainty. 


\section{9 \\ 1. Introduction}

50 Identifying and quantifying the source(s) of aeolian sediments is a long-standing

51 challenge for geoscientists, and yet such information is often of crucial importance in

52 understanding sediment fluxes at a range of scales. As well as providing

53 fundamental knowledge on long-term landscape evolution (e.g. Pell et al., 1997),

54 aeolian provenance studies have been used to elucidate past wind regimes and

55 palaeoclimates (e.g. Nanson et al., 1995), investigate hazardous dust transport

56 pathways (e.g. Pethierick et al., 2008; Yang et al., 2007) and inform studies of the

57 palaeoclimatic record of the Antarctic ice-core dust record (Delmonte et al., 2010;

58 Delmonte et al., 2004). The challenges with the task arise not just from the diverse

59 range of potential sources for aeolian sands and dusts (e.g. geological or lithological

60 units, soil units, land use types and geomorphological landscapes), and the long

61 transport distances which may be involved (on the order of $10-10^{2} \mathrm{~km}$ for aeolian

62 sand and $10-10^{3} \mathrm{~km}$ for aeolian dust), but also the potential complexity of transport

63 pathways (Huntsman-Mapila et al., 2005). Before deposition at its current location,

64 an aeolian sand grain may have been through multiple cycles of fluvial, aeolian,

65 lacustrine and/or colluvial deposition and subsequent mobilization. Aeolian sands,

66 therefore, rarely retain an easy-to-interpret signature of their origins.

68 The use of geochemical fingerprinting methods to determine sediment provenance 69 has progressively increased since the late 1990s (Walling, 2013). Application has 70 been focused most widely in fluvial contexts (Haddadchi et al 2013) wherein there 71 recent work has highlighted the need to pay attention to challenges in signature 72 development and tracer behavior (Koiter et al., 2013). Sediment fingerprinting 73 involves the identification, quantification and statistical testing of a range of source 
74 material properties capable of discriminating between potential sediment sources

75 with a view to improving knowledge of sediment source and transport processes 76 (Collins et al., 2017). These properties may include geochemical characteristics 77 (e.g. Douglas et al., 2009; Lin et al., 2015), radionuclide concentrations (Wilson et al., 2012), mineralogy (Pittam et al., 2009), geochronological data (principally U-Pb dating of detrital zircons; e.g. Pell et al., 1997; Garzanti et al., 2013), biomarkers

80 (Chen et al., 2016) and colour properties (Martínez-carreras et al., 2010). Although 81 sediment fingerprinting studies of aeolian sands are not new (e.g. Pell et al., 1997; Wasklewicz and Meek, 1995; Winspear and Pye, 1996; Liu et al., 2016; Muhs et al, 2017), challenges remain in adequately capturing the uncertainties associated with the diverse sources and pathways that may exist, and adoption of techniques developed in different disciplines offer a route forward. It is noteworthy that in a recent review discussing applications of sediment source-tracing methods (Owens et al., 2016), mention of aeolian sedimentation is limited to health science studies of PM2.5 and PM10 material. The opportunity to utilize these approaches in aeolian process science remains largely overlooked.

In recent years, increasing attention has been directed to the uncertainty of the 92 results generated by sediment source fingerprinting. It is important that such 93 uncertainty is recognized, particularly if the results are to be used to target 94 investment in sediment control measures (Mukundan et al., 2012). The factors 95 contributing to uncertainty in estimates of source apportionment are manifold and 96 diverse, and have been reviewed elsewhere (e.g. Walling 2010; Koiter et al., 2013;

97 Collins et al, 2017); here we consider some of the differences between the fluvial 98 setting of most sediment fingerprinting studies, and the aeolian context considered 
99 here. Many uncertainties remain the same - for instance, instrumental precision.

100 Other aspects of the aeolian entrainment, transport and depositional system, 101 however, differ markedly from fluvial settings. Due to dominance of gravity in 102 controlling - and directing - slope and fluvial processes, and the (usually) confined 103 nature of fluvial systems, erosion and entrainment of sediment from catchments is 104 highly directionally-controlled. In an aeolian context, there is more scope for spatially 105 extensive direct entrainment of sediment, and also more potential for directional 106 variability, and this complex mixing environment may in turn lead to increased 107 covariance between properties used to derive the fingerprint. In addition, such 108 complexities cannot be considered static, as variations in wind regimes over long 109 timescales may lead to changes in these pathways.

111 In order to quantify the uncertainty associated to mixing models related to this 112 inherent variability in the source area and sediment mixture data, some recent 113 studies have explored the use of Monte Carlo simulations (e.g. Motha et al., 2003; 114 Collins et al., 2013; Collins et al., 2012; Stone et al., 2014; Smith \& Blake, 2014; 115 Sherriff et al., 2015; Vale et al., 2016; Gellis \& Noe, 2013; Voli et al., 2013; Wilkinson 116 et al., 2013; Walling et al., 2008). More recently, Bayesian mixing models being 117 employed more comprehensively translate component uncertainties into source 118 apportionment results (Cooper and Krueger, 2017) with several examples 119 undertaken in hydrological contexts (e.g. Fox \& Papanicolaou, 2008; Cooper et 120 al.,2014; Cooper et al., 2015; Nosrati et al., 2014; Stewart et al., 2015). To date, 121 however, such approaches have not been used within aeolian sedimentary contexts. 
123 The sophistication of aeolian sediment provenance studies currently lags those in 124 the fluvial sphere, and the main aim of this paper is to demonstrate the viability of 125 fingerprinting methods for aeolian sediments, including the estimation of uncertainty, 126 associated with the contributions from different geological units as potential sources 127 for a small dunefield, Ashkzar Erg, in the Yazd-Ardekan Plain, central Iran, using a 128 Bayesian mixing model. Ashkzar erg and its surrounding potential sources cause 129 many serious problems related to wind erosion and associated on-site and off-site 130 effects, with potential impacts on the health of the occupants of the neighbouring city 131 of Yazd (Naddafi et al., 2006). Aeolian deflation is a major erosional process on the 132 Yazd-Ardekan Plain and large amounts of aeolian sediment are often transported to 133 residential regions by wind (Amiraslani and Dragovich, 2011). Therefore, quantifying 134 sediment source contributions to the Ashkzar sand dunes could help to select the 135 best management strategies at this location and others similarly affected by aeolian 136 erosion. Additionally, the findings are considered in their geomorphological context 137 with the aim of explaining the spatial variability in sediment provenance observed at 138 Ashkzar erg.

\section{Materials and methods}

\subsection{Field location}

Yazd-Ardekan $\left(31^{\circ} 10^{\prime}-32^{\circ} 43^{\prime} \mathrm{N}, 5^{\circ} 68-54^{\circ} 47^{\prime} \mathrm{E}\right)$ is an arid plain in central Iran, 143 and includes different geomorphic landscapes, such as the Ashkzar and Yazd ergs 144 (Figure 1). The Yazd-Ardekan Plain is surrounded by mountain ranges. These are 145 Shirkooh in the south, Ahangaran and the Margh Zard Mountains in the west, Haft 146 Adamin and Khoonzad Mountains in the east and Chak Chak Mountain in the north.

147 The area of the plain is $\sim 2900 \mathrm{~km}^{2}$, and it consists of $78 \%$ Quaternary alluvial fans 
148 and terraces ( $\mathrm{Qt}_{2}$ geological unit), 13\% clay flats (Qc geological unit), 7\% Eocene 149 gypsiferous marl (Egm geological unit) and 2\% sand dunes (Qsd geological unit) 150 (Figure 1 and 2). About 93\% of Yazd-Ardekan Plain is thus covered by Quaternary 151 deposits. Active and stabilized sand dunes in the Ashkzar erg occupy $58 \mathrm{~km}^{2}$ 152 (centred on $32^{\circ} 1^{\prime} \mathrm{N}, 54^{\circ} 10^{\prime} \mathrm{E}$ ), which is dominated by barchans and transverse 153 barchanoid ridges (Figure 2). The erg has a sparse but extensive cover of Haloxylon 154 persicum, a species which is both endemic to the region, and is also used to stabilize 155 mobile sand (Amiraslani and Dragovich, 2011). Based on 50 years of climate data at 156 Yazd Meteorological Station, minimum and maximum annual temperatures are -16 $157{ }^{\circ} \mathrm{C}$ and $46{ }^{\circ} \mathrm{C}$, respectively. Long-term mean rainfall and annual evaporation in the study area are $\sim 60 \mathrm{~mm} /$ year and $\sim 3500 \mathrm{~mm} /$ year respectively. According to annual wind roses, dominant winds on the Yazd-Ardekan Plain are mainly from the north 160 and west (Figure 1C).

161

162

[Approx. location of Figure 1]

163

164

\subsection{Sampling and laboratory analysis}

The geological units that were identified as potential sources for sand dunes (Qsd 166 formation) are the Qt2 (Quaternary alluvial fans and terraces), Qc (Quaternary clay 167 pans and flats) and Egm (Eocene marls) formations. Other surrounding lithologies in 168 the vicinity are hard, igneous exposures and can be discounted from generating 169 substantial quantities of deflatable sediment. In this study, spatially distributed 170 source samples were taken from 49 sites, covering the Egm $(n=8), Q c(n=18)$ and 171 Qt2 $(n=23)$ potential sources, and eight sediment samples were collected from the 172 Ashkzar sand dunes (Figure 1D). Samples were collected from the upper 0-5 cm 
173 depth of potential sources (that is, the layer of the regolith exposed to current aeolian 174 entrainment) and sand dunes (that is, the layer of the regolith most recently 175 deposited); this is similar to sampling strategies employed by other provenance 176 studies of aeolian dunes (e.g. Pell et al., 1997), and is accordance with common 177 earth science protocols (Owens et al., 2016). Within each source area, sample 178 selection was based upon locations that were: a) clearly derived from the geological 179 unit in question, b) selected to ensure broad spatial coverage of the source area, and 180 c) clearly influenced by aeolian erosion (e.g. the presence of deflatable unvegetated sand surfaces with ripples, as well as yardangs of a range of scales). Samples numbers were chosen to ensure a balance between the greater spatial extent of the Qt2 unit (i.e. sampling was stratified), whilst maintaining a minimum of eight samples for the smaller Egm and Qc units. The spatial location of sampling sites is shown in Figure 1D.

All sand dune and potential source samples were dry sieved for particle size data, and to isolate the $62.5-150 \mu \mathrm{m}$ fraction for further geochemical analysis. This fraction was chosen as it represents the dominant fraction in each of the dune samples (Table 1), and is of a size range susceptible to aeolian transport (whilst excluding any contribution of larger grains from local sources, either by aeolian creep or other transport processes). Concentrations of elements including major, trace and rare earth elements (REE) were determined using ICP-MS, after direct digestion with 193 aqua regia (e.g. Collins et al., 2010; Collins et al., 2012); and concentration of strontium and neodymium isotopes measured by ICP-MS, after digestion with a mixture of $\mathrm{HNO}_{3}+\mathrm{HClO}_{4}+\mathrm{HF}$ (3:2:1) (e.g. Honda et al., 2004; Rao et al., 2011). The relative standard deviation (\%RSD), based on three replicates for each determinant 
198 REE ratios including $\sum$ REE, Nd/Yb, Eu/Eu (Europium Anomaly), (La/Lu)n, (La/Sm)n, $199(\mathrm{Gd} / \mathrm{Yb})_{\mathrm{n}},(\mathrm{La} / \mathrm{Yb})_{\mathrm{n}}$ and $\delta \mathrm{Ce}$ (Cerium Anomaly) were calculated (e.g. Daga et al., 200 2008; Dou et al., 2010; Rao et al., 2011). In total, 61 tracers were used to fingerprint 201 the sediments of the Yazd-Ardekan Plain.

202

203 [Approx. location of Table 1]

204 [Approx. location of Figure 2]

205 [Approx. location of Figure 3]

206

207

\subsection{Discrimination of aeolian sediment sources}

208

We employed a two-stage statistical method proposed by Collins and Walling (2007)

209

to characterize the composite fingerprint for the sources of the sands of the Ashkzar

210 dunes. In stage one, all individual fingerprint properties were tested for their ability to distinguish source types, using the Kruskal-Wallis H-test. Properties with critical

212 values at the $95 \%$ level of confidence could be used in a composite fingerprinting 213 model to discriminate between sources types. In stage two, stepwise discriminant 214 function analysis (DFA) was employed to identify the optimum composite fingerprint 215 model from the properties selected in stage one. The stepwise DFA was based on 216 the minimization of Wilk's lambda was used to select optimum composite fingerprint. 217 The $F$ values were used as the test criteria to enter and remove elements. The 218 threshold of $F$ value for entering and removing of elements was set to 3.84 and 2.71, 219 respectively (e.g. Vale et al, 2016).

\subsection{Bayesian mixing model}


221 End-member mixing models have been taken a variety of approaches to account for 222 uncertainty in the mixing model (Cooper and Krueger, 2017) and some (e.g. Brewer 223 et al., 2005; Fox \& Papanicolaou, 2008) have adopted hierarchical Bayesian models, 224 which we adopt here. Within the mixing model formulation, we assume that, for each 225 source $s$, the sample $i$ tracer composition, $x$, has a multivariate normal distribution as 226 follows:

227

$$
\mathrm{x}_{\mathrm{s}}^{\mathrm{i}} \sim \mathrm{MVN}_{\mathrm{A}}\left(\mu_{\mathrm{s}}, \sum_{\mathrm{s}}\right), \quad \mathrm{s}=1, \ldots, \mathrm{N}, \quad \mathrm{i}=1, \ldots, \mathrm{n}_{\mathrm{x}, \mathrm{s}}
$$

228

229

230

231

232

233

234

235

236

237

238

239

240

241

242

where $n_{x, s}$ indicates the number of samples of source $s ; \mu_{s}$ is a A-dimensional vector representing mean fingerprints for source $s ; \sum_{s}$ represents a $(A \times A)$ dimensional covariance matrix for source $\mathrm{s}$. There are $n_{z}$ sediment samples for which $A$ fingerprints were measured for each sample $\mathrm{Z}^{\mathrm{j}}=\left(\mathrm{z}_{1}^{\mathrm{j}}, \ldots, \mathrm{z}_{A}^{\mathrm{j}}\right)^{\mathrm{T}}, \mathrm{j}=1, \ldots, \mathrm{n}_{\mathrm{z}}$ and these fingerprints have multivariate normal distributions:

$$
\mathrm{Z}^{\mathrm{j}} \sim \mathrm{MVN}_{\mathrm{A}}\left(\mu_{\mathrm{j}}^{\mathrm{z}}, \mathbb{2}^{\mathrm{z}}\right)
$$

Each source $s$ has a fractional contribution $p_{s}^{j}$ to each sediment sample $j$. The contribution of source types for each sediment sample is equal to $p_{s}^{j} y_{s}^{j}$, where $y_{s}^{j}$ is an unobserved (latent) variable that follow the same distribution as $X_{s}^{i}$.

$$
\begin{gathered}
\mu_{j}^{\mathrm{z}}=\sum_{\mathrm{s}=1}^{\mathrm{N}} \mathrm{p}_{\mathrm{s}}^{\mathrm{j}} \mathrm{y}_{\mathrm{s}}^{\mathrm{j}}, \quad \mathrm{j}=1, \ldots, \mathrm{n}_{\mathrm{z}} \\
\sum_{\mathrm{s}=1}^{\mathrm{N}} \mathrm{p}_{\mathrm{s}}^{\mathrm{j}}=1, \quad 0 \leq \mathrm{p}_{\mathrm{s}}^{\mathrm{j}} \leq 1
\end{gathered}
$$

Each fractional contribution must be between zero and one, positive and all of them must sum to unity. To meet this constraint, some studies have used Dirichlet distribution as a prior for the fractional contribution (e.g. Fox \& Papanicolaou, 2008; Massoudiehet al., 2013), whereas other studies used transformation such as 
243 centered log-ratio (CLR) (Semmenset al., 2009), isometric log-ratio (ILR) (e.g.

244 Cooper et al., 2015; Parnell et al., 2013; Egozcue et al., 2003) and additive log-ratio 245 (ALR) (e.g. Brewer et al., 2005; Palmer \& Douglas, 2008). In this study, a CLR 246 transformation was used, as it has been shown to produce comparable median 247 values to other methods, but with better precision (Cooper et al., 2014). The 248 transformation applied is thus:

$$
\phi_{i}=C L R\left(P_{i}\right)=\log \left[\frac{P_{i 1}}{g\left(P_{i}\right)}, \ldots, \frac{P_{i k}}{g\left(P_{i}\right)}\right]
$$

250

$$
\phi_{i \sim}\left(\mu_{\varnothing}, \tau_{\varnothing}\right)
$$

251 where $g\left(p_{i}\right)$ is the geometric mean of the proportion vector. Figure 4 shows a 252 directed acyclic graph of the model. Compared to an empirical Bayesian approach 253 in which some prior parameters are estimated using deterministic data, the full 254 Bayesian approach employed here needs to specify prior distribution for all 255 parameters. When there is little information about the parameters, using informative 256 hyper-parameters cause biased results. In this study, weakly or non-informative 257 hyper-parameters were used. Multivariate normal and inverse-Wishart distributions 258 were selected as prior distribution for sources means and covariance matrix, 259 respectively.

$260 \mu_{s}^{X} \sim \operatorname{MVN}\left(\theta_{s}, \tau_{\mathrm{s}}^{-1}\right), \quad \mathrm{s}=1, \ldots, \mathrm{N}$

$261 \sum_{s}^{X} \sim$ Inverse - Wishart $\left(\Omega_{\mathrm{s}}^{\mathrm{X}}, \rho_{s}^{X}\right), \quad \mathrm{s}=1, \ldots, \mathrm{N}$

262 Here, the hyper-parameter $\theta_{s}$ was set to the sample means of the fingerprints and $263 \tau_{\mathrm{s}}$ was set as a diagonal matrix with values 0.01 on the diagonal. For Wishart 264 distribution, the hyper-parameter $\Omega_{\mathrm{S}}^{\mathrm{X}}$ is a diagonal matrix with value 1 as diagonal 
265 elements and $\rho_{S}^{X}$ was set to six (to reflect the lack of information on the precision 266 matrices, and the number of tracers selected for the fingerprint). Similar prior 267 distribution and hyper-parameters was assigned for sediment covariance matrix.

$268 \sum^{Z} \sim$ Inverse - Wishart $(\Omega, \rho)$

269 Weakly informative hyper-parameters $\mathrm{N}(0,1)$ and Inv- $\Gamma(2,1)$ were assigned for $270 \mu_{\phi}$ and $\tau_{\phi}$, respectively.

271 The complete posterior distribution of all model parameters for sediment sample $Z_{j}$ 272 can thus be written as

$\left(\Sigma_{S}, \tau_{\phi}, \mu_{\phi}, \Sigma^{\mathrm{Z}}, p_{j}, \phi, \mu_{S} \mid X, Z_{j}\right) \propto \prod_{S=1}^{N} \prod_{i=1}^{n_{x, S}}\left\{P\left(x_{S}^{i} \mid \mu_{S}, \Sigma_{\mathrm{S}}\right)\right\} \times \prod_{S=1}^{N} P\left(\mu_{S} \mid \theta_{S}, \tau_{S}^{-1}\right) \times$

274

$\prod_{S=1}^{N} P\left(\Sigma_{\mathrm{S}} \mid \Omega_{\mathrm{S}}, \rho_{\mathrm{S}}\right) \times P\left(Z_{j} \mid \mu_{j}^{Z}, \Sigma^{\mathrm{Z}}\right) \times P\left(\Sigma^{\mathrm{Z}} \mid \Omega, \rho\right) \times P\left(\phi \mid \mu_{\phi}, \tau_{\phi}\right) \times P\left(\mu_{\phi}\right) \times P\left(\tau_{\phi}\right)$

275

(eq.10)

276

277

278

279

280

281

282

283

284

285

286 287

As the joint posterior of all parameters is complex and high-dimensional, we cannot directly obtain posterior distribution functions, but the Bayesian model thus defined can be analyzed using Markov Chain Monte Carlo (MCMC); we have used the WinBUGS package (Lunn et al., 2000) to derive parameter estimates. MCMC methods require that the chain reaches a steady state, and the number of runs required to reach this state is considered as burn in. The model was run by taking $50,000,000$ times from the posterior distribution from the sand dune and source samples, and the first 5,000,000 runs were considered as burn in. The large number of iterations was used to ensure convergence, despite the model's complexity and high dimensionality; the model converged during the run, as assessed by trace plots of simulations, Monte Carlo error and autocorrelation. 
288 [Approx. location of Figure 4]

289

290

\section{Results}

291

Grain size data are presented in Table 1 to enable consideration of potential sorting

292

293

294

295

296

297

298

299

300

301

302

303

304

305

306

307

308

309

310

311

312

effects during aeolian transportation. The sources reveal very similar physical grain sizes, and it is worth noting that whilst the Qc unit is mapped as a 'clay flat', the sediment sampled for analysis is dominantly sand. The erg, on the other hand, as might be expected as a result of aeolian transport and deposition is better sorted, and less enriched in the coarse and very coarse sand fraction. The individual dune sand samples retain marked variability, with the very-fine $(62.5-150 \mu \mathrm{m})$ fraction ranging from $37 \%$ to $65 \%$, and a single sample (8) retaining a substantial coarse (> $600 \mu \mathrm{m})$ component.

The Kruskal-Wallis $\mathrm{H}$ test (i.e. one-way ANOVA) was performed on geological units Egm, Qc and Qt2. Results identified 25 significant tracers between these groups (Table 2). Tracers that failed this test $(p>0.05)$ were removed. These were: $\mathrm{Nd}$, Sm, Gd, Tb, Dy, Yb, Lu, (Nd/Yb), (Gd/Yb $)_{n},(\mathrm{La} / \mathrm{Sm})_{\mathrm{n}}, \mathrm{V}, \mathrm{Cr}, \mathrm{Co}, \mathrm{Ni}, \mathrm{Cu}, \mathrm{Zn}, \mathrm{Y}, \mathrm{Zr}, \mathrm{Nb}, \mathrm{Ta}$, U, As, Bi, Cd, Ge, In, Mo, Sb, Se, Te, W, Mn, Si, ${ }^{143} \mathrm{Nd},{ }^{144} \mathrm{Nd}$ and ${ }^{86} \mathrm{Sr}$. Whilst the successful discrimination of different tracers between geological units will vary when this method is applied to settings other than this location, the presence of 25 tracers with significant discriminatory power suggests that this method may be applicable in diverse geological settings and/or areas with contrasting weathering regimes.

\section{[Approx. location of Table 2]}


313 According to the DFA, a total of six individual tracer properties $\left(\mathrm{Rb}, \mathrm{Sr},{ }^{87} \mathrm{Sr}\right.$,

$314(\mathrm{La} / \mathrm{Yb})_{n}, \mathrm{Ga}$ and $\left.\delta \mathrm{Ce}\right)$ were selected for the optimum composite fingerprint, which

315 correctly discriminated $81.6 \%$ of the source type samples (Figure 5).

316

317 [Approx. location of Table 3]

318 [Approx. location of Figure 5]

319

320

321

Although DFA results suggested that good source discrimination was achieved, with clear separation of the three group centroids, samples sourced from Qc were found to slightly overlap with the Qt2 source when the first two discriminant functions were plotted, and, to a lesser degree Qt2 and Egm also overlap slightly (Figure 5). The mean and SD of six optimum composite fingerprints that were selected for the

325 Bayesian mixing model, are presented in Table 3. These were tested for normality 326 via Wilks-Shapiro tests (Table 4), and the raw data revealed that the $\mathrm{Sr}$ and $\delta \mathrm{Ce}$ 327 tracers did not follow a normal distribution for all settings. To account for this, Box328 Cox transformations (Box and Cox, 1964) were applied to all data, and the 329 transformed data were used for model experimentation.

331 [Approx. location of Table 4]

333 The derived source contributions for the eight sand dune samples are presented in 334 Table 5 and Figure 6. Overall, the alluvial fans and terraces (Qt2) provide the most 335 abundant supply of sands (mean contribution across all 8 samples $=45.4 \%$, and 336 locally up to 92.7\%), with the clay pans (Qc) and Eocene marls (Egm) each 337 contributing around a quarter of the net sediment aeolian flux. However, the 338 composition of the dune sands is highly variable, with different samples dominated 
339 by different contributing sources, and locally, all three of the potential sources occur 340 as both maxima and minima.

341

342 [Approx. location of Figure 6]

343

344 4. Discussion

345

4.1 Development of a Bayesian mixing model to discriminate aeolian sediment

346

pathways

347 The mixing model to fingerprint aeolian sediment sources deployed in this study

348 used composite signature comprising a suite of six geochemical characteristics (Rb,

$349 \mathrm{Sr},{ }^{87} \mathrm{Sr}, \mathrm{La}: \mathrm{Yb}, \mathrm{Ga}$ and $\delta \mathrm{Ce}$ ) identified by stepwise DFA as the most appropriate, 350 and was able to account for $>82 \%$ of the variance between the three sources. The 351 suite of properties selected by the DFA method most likely reflects two principal 352 factors; the ultimate source of the sediments, and the degree of weathering. The 353 latter might well have variable influence across the source areas, and hence there is 354 some overlap between samples of each class. High La:Yb ratios, for instance, are 355 typically associated with deep igneous lithogenesis (Deffant and Drummond, 1990) 356 and may locally reflect differing sediment contributions from the Precambrian 357 crystalline basement provinces of central Iran. $\delta \mathrm{Ce}$, similarly, is often associated with 358 intrusive igneous rocks, although may also be enriched in some sedimentary rocks 359 (Wedepohl, 1978); in this study, the highest concentrations are found in the alluvial 360 fans derived from the adjacent igneous mountains, but the second highest 361 concentrations are found in the sedimentary marls of the Egm unit (Figure 2). In 362 short, the highly varied geology of central Iran, ranging from Precambrian magmatic 
363 rocks to Cenozoic marine sediments, promotes a high degree of variance in the 364 geochemical fingerprint of modern aeolian sediments. Compounding this is the range 365 of weathering intensities seen, from the intense weathering history of the sediments 366 of Quaternary clay pans, to the more moderate weathering of the sands of the 367 alluvial fans forming the piedmonts of the neighbouring ranges.

\subsection{Potential for application to other aeolian depositional settings}

369 Despite the usefulness of understanding the provenance of aeolian sands, the sophistication of unmixing models within the aeolian science community generally lags that of fluvial science, in particular in terms of the numerical underpinning of methods applied. Indeed, many such studies attempt to derive provenance estimates only qualitatively (e.g. Fitzsimmons et al, 2009), or, in the few recent cases where robust unmixing models have been applied, relatively simple approaches to 375 incorporating uncertainty into models have been taken (e.g. Liu et al., 2016).

The successful application of a Bayesian model within an MCMC framework to aeolian sands of a small erg in this study demonstrates the potential of this approach more widely. It is particularly likely to complement detrital zircon $\mathrm{U}-\mathrm{Pb}$ dating 379 provenance studies, and may prove especially useful in settings where there are insufficient zircon grains to enable the application of this method (e.g. Jia et al., 2015, Nie and Peng, 2014, Ren et al., 2014, Thorpe et al., 1992). Further application of the methods demonstrated here is required to test the ability of such methods globally, but these results suggest a promising future, and a new direction for aeolian provenance studies. For instance, it would be useful to explore the power of these methods in larger-scale settings, such as the continental dunefields of southern 
387 relationship between tectonic setting and sedimentation (e.g. Garzanti et al., 2014) 388 and explore the long-term evolution of landscapes (e.g. Pell et al., 1997; 2000). This 389 will also elucidate the importance of diversity of local geology and weathering 390 regimes in producing sufficiently distinctive fingerprints.

391 Accurate propagation of the uncertainties associated with the component 392 contributions is also a valuable aspect of the methodology employed here and allows 393 more realistic interpretation of the data. For instance, the most abundant two source 394 components of samples $E(Q t 2=62.3 \% ; Q c=23 \%)$ and $D(E g m=56.3 \%$; $Q c=$ $39528.7 \%$ ) might suggest similar proportions of the major components at these dunes; 396 roughly 60:25. However, consideration of the lower confidence of the fingerprint of 397 sample D (Figure 6) reveals that whilst the composition of this sample is much more 398 open to interpretation, sample $\mathrm{E}$ is quite clearly dominated by the alluvial fan-derived 399 sands (Qt2).

400

401

\section{$\underline{4.3 \text { Implications for aeolian sediment transport pathways }}$}

402 Overall, the surrounding Quaternary fans and terraces contribute most $(\sim 45 \%)$ to the 403 composition of Ashkzar erg; yet this is a disproportionately low value, given that they 404 represent $78 \%$ of the surrounding area. Conversely, the size of the overall 405 contributions from the Quaternary clay flats ( 26\%) and Eocene marls $(\sim 28 \%)$ to the 406 samples studied reveals the importance of these landscape units as sediment 407 sources, given that these units occupy only $13 \%$ and $7 \%$ of the surrounding area, 408 respectively. The importance of the marls as a source sediment, which outcrop only 409 to the north of the Ashkzar dunefield, suggests that net wind regime alone cannot be 410 considered as indicative of the net sediment transport in the region (Figure 1), as 
411 westerly winds are equally strong here yet import much less sediment. Both the wind 412 regime and potential sediment sources must be considered when evaluating net 413 aeolian sediment flux.

414 There is much spatial variation in the composition of the dune sands of Ashkzar erg 415 (Figure 6). Even before the geochemical composition of these sands in considered, 416 such variability is evident from the differing grain size profiles in the eight samples 417 investigated here (Table 1). Sample G, from the far south of the dunefield, contains $418 \sim 20 \%$ coarse sands (defined here as $>600 \mu \mathrm{m}$ ), an unusually high figure for an 419 aeolian dune, although this sample is taken close to the border with the mapped 420 region of slipfaceless dome dunes, which tend to accumulate from coarser sands 421 (Lancaster, 1995). That said, sample H, from within the dome dunes, is not unusually 422 coarse.

423 Broadly, and considering the uncertainties presented by the methodology proposed 424 herein, two groups can be discerned within the samples geochemically analysed for 425 provenance (Figure 6). Samples taken from along the south and west of the 426 dunefield ( $B, E, F$ and $G$ ) are dominated to varying degrees by sediment from the 427 surrounding Quaternary fans and terraces (i.e. source unit Qt2), whereas most 428 samples to the north and east $(A, D$ and $H)$ show much greater contributions from 429 the Eocene marls (Egm) and clay flats (Qc). However, the division is not clear-cut; 430 sample C, in the northeast of the dunefield, has a dominant component from the Qt2 431 unit (with the second component only very slightly overlapped at $2 \sigma$ confidence 432 levels).It is, perhaps, unsurprising that the more northerly samples tend to show an 433 increased input from the Eocene marls (Egm), as these units have been shown to 434 contribute disproportionately to the sediment flux in the area, and also outcrop 435 exclusively on the northern side of the valley (Figure 1). 
436 The provenance of the sands is even less readily correlated with dune morphology,

437 with the Qt2-dominated sands occurring within three defined dune morphological 438 zones (barchans, barchanoid ridges and asymmetrical barchans). Samples A and B, 439 the closest pair of samples studied ( $2.2 \mathrm{~km}$ apart), yield very different provenance 440 fingerprints, despite both lying within the region of Ashkzar erg dominated by 441 barchanoid ridges. The overall morphology of the dunes (Figure 3) supports spatially 442 and /or temporally variable sediment availability, with the transformation of barchans 443 to barchanoid ridges essentially being sediment-supply controlled, and asymmetric 444 barchan/linear forms believed to be the result of asymmetries of sediment supply, or 445 changes to the wind regime (Bagnold, 1941; Lancaster 1995).

446 The heterogeneity in the sediment provenance evident here suggests that either a) 447 some kind of fractionation of the aeolian sediment flux is occurring, with different 448 sources depositing sediment at different locations or b) different sediment transport 449 pathways have been active intermittently and asynchronously during the formation of 450 the dunefield. The similar physical composition (i.e. grain size) of the sources, and 451 the lack of evidence of systematic variation across the dunefield, would tend to 452 support the latter suggestion. Different sediment pathways might result from different 453 sources become more or less active over time, or might result from changing wind 454 regime over long (i.e. late Quaternary) timescales. The heterogeneity evident also 455 suggests that during dune accumulation periods, large-scale mixing of aeolian sands 456 from different sources (which might be expected given transport distances of 10-50 $457 \mathrm{~km}$ ) is not occurring. In the absence of any chronological control for these dunes, 458 such hypotheses cannot be conclusively tested currently, but establishing the 459 relative roles of spatial and temporal variability in dune accumulation would be a 460 worthwhile exercise. 


\section{5. Conclusion}

463 In dryland environments, understanding the main sources for aeolian sediments is 464 an essential step in developing management strategies to reduce aeolian sediment 465 loadings and wind erosion. Establishing aeolian sediment pathways, however, is not 466 usually straightforward and is complicated when multiple potential source areas 467 might contribute to a region of net sand accumulation. The method proposed here, 468 based on methodologies applied to fluvial sediments, uses a suite of geochemical 469 data to identify the most apposite characteristics (the 'fingerprint') for discerning 470 superficially similar sources of aeolian sediment. Whereas these methods have 471 become widely adopted in fluvial geomorphology and catchment science over the 472 past two decades, they remain almost unused in aeolian science. Here, it has been 473 successfully demonstrated on fine sand in a small dunefield in central Iran, but it 474 might be applied equally to dust (i.e. silt) flux, although longer transport distances are 475 liable to prove more difficult to fingerprint unless relatively discrete and distinct 476 sources can be identified. The use of MCMC methods to provide confidence 477 estimates in the mixing model output enables more rigorous interpretation of the 478 relative importance of different sediment sources.

480 This method revealed within Ashkzar erg unexpected spatial heterogeneity of dune 481 composition (and thus provenance), which has a complex relationship with the 482 position within the dunefield, the dune type and other physical characteristics. The 483 Eocene marls in the surrounding area have been shown to contribute 484 disproportionately to the sediments of the dunes. In terms of management of sand 485 and dust hazard at this location, both the original source areas and those parts of the 
486 dunefield enriched in the Egm component might be viewed as priority targets for 487 landscape stabilization efforts, due to their apparent propensity for aeolian 488 mobilization.

489

490 More widely, the methods proposed here for aeolian provenance unmixing method 491 can be applied to any mixed-source aeolian sediment to elucidate differing 492 susceptibilities to aeolian deflation, and reveal transport pathways at timescales 493 longer than those possible by either field study or remote sensing. Disciplines which 494 might benefit from the adoption of such methods include not just aeolian 495 geomorphology, but also dryland land management, soil science, engineering 496 geology and potentially palaeoenvironmental and palaeoclimatological studies. A 497 combination of the methods presented herein with geochronological studies may 498 enable calculation of flux rates to provide quantification of long-term sediment fluxes, 499 even when, as is very often the case with aeolian sediments, transport pathways are 500 complex and multi-phase.

501

502

503

\section{References}

504 Amiraslani, F. and Dragovich, D. (2011). Combating desertification in Iran over the 505 last 50 years: An overview of changing approaches. Journal of Environmental $506 \quad$ Management 92 (1), 1-13. doi: 10.1016/j.jenvman.2010.08.012.

507 Bagnold, R.A. 1941. The physics of blown sand. Methuen, London.

508 Box, G.E.P \& Cox, D.R. (1964). An analysis of transformations. Journal of the Royal 509 Statistical Society, Series B. 26 (2): 211-252. 
510 Brewer, M. J., Filipe, J. A. N., Elston, D. A., Dawson, L. A., Mayes, R. W., Soulsby, 511 Ch., \& Dunn, S. M. (2005). A Hierarchical Model for Compositional Data 512 Analysis. Journal of Agricultural, Biological, and Environmental Statistics, 10(1), 513 19-34. doi:10.1198/108571105X28200

514 Chen, F., Fang, N., \& Shi, Z. (2016). Using biomarkers as fi ngerprint properties to 515 identify sediment sources in a small catchment. Science of the Total 516 Environment, 557-558, 123-133. doi:10.1016/j.scitotenv.2016.03.028

517 Collins, A. L., \& Walling, D. E. (2007). Sources of fine sediment recovered from the 518 channel bed of lowland groundwater-fed catchments in the UK. Geomorphology, $519 \quad 88,120-138$. doi:10.1016/j.geomorph.2006.10.018

520 Collins, A. L., Zhang, Y., McChesney, D., Walling, D. E., Haley, S. M., \& Smith, P. 521 (2012). Sediment source tracing in a lowland agricultural catchment in southern 522 England using a modified procedure combining statistical analysis and 523 numerical modelling. Science of the Total Environment, 414, 301-317. 524 doi:10.1016/j.scitotenv.2011.10.062

525 Collins, A. L., Zhang, Y. S., Duethmann, D., Walling, D. E., \& Black, K. S. (2013). 526 Using a novel tracing-tracking framework to source fine-grained sediment loss to 527 watercourses at sub-catchment scale. Hydrological Processes, 27(6), 959-974. 528 doi:10.1002/hyp.9652

529 Collins, A. L., Zhang, Y., Walling, D. E., Grenfell, S. E., \& Smith, P. (2010). Tracing 530 sediment loss from eroding farm tracks using a geochemical fingerprinting 531 procedure combining local and genetic algorithm optimisation. Science of the 532 Total Environment, 408(22), 5461-5471. doi:10.1016/j.scitotenv.2010.07.066 
533 Collins, A. L., Zhang, Y., Walling, D. E., Grenfell, S. E., Smith, P., Grischeff, J., ... 534 Brogden, D. (2012). Quantifying fine-grained sediment sources in the River Axe 535 catchment, southwest England: Application of a Monte Carlo numerical 536 modelling framework incorporating local and genetic algorithm optimisation. 537 Hydrological Processes, 26(13), 1962-1983. doi:10.1002/hyp.8283

538 Collins, A.L., Pulley, S., Foster, I.D.L., Gellis A., Porto, P., Horowitz, A.J. (2016). 539 Sediment source fingerprinting as an aid to catchment management: A review of 540 the current state of knowledge and a methodological decision-tree for end541 users. Journal of Environmental Management, 194, 86-108. $542 \quad$ doi.org/10.1016/j.jenvman.2016.09.075

543 Cooper RJ and Krueger T (2017, in press). An extended Bayesian sediment 544 fingerprinting mixing model for the full Bayes treatment of geochemical 545 uncertainties. Hydrological Processes. DOI: 10.1002/hyp.11154.

546 Cooper, R. J., Krueger, T., Hiscock, K. M., \& Rawlins, B. G. (2014). Sensitivity of 547 fluvial sediment source apportionment to mixing model assumptions: A 548 Bayesian model comparison. Water Resources Research, 9031-9047. 549 doi:10.1002/2014WR016194.

550 Cooper, R. J., Krueger, T., Hiscock, K. M., \& Rawlins, B. G. (2015). High-temporal 551 resolution fluvial sediment source fingerprinting with uncertainty: A Bayesian 552 approach. Earth Surface Processes and Landforms, 40(1), 78-92. $553 \quad$ doi:10.1002/esp.3621

554 Daga, R., Ribeiro Guevara, S., Sánchez, M. L., \& Arribére, M. (2008). Source 555 identification of volcanic ashes by geochemical analysis of well preserved 
556 lacustrine tephras in Nahuel Huapi National Park. Applied Radiation and 557 Isotopes, 66(10), 1325-1336. doi:10.1016/j.apradiso.2008.03.009

Delmonte, B., Baroni, C., Andersson, P.S., Schoberg, H., Hansson, M., Aciego, S.,

577 Egozcue, J. J., Pawlowsky-Glahn, V., Mateu-Figueras, G., \& Barceló-Vidal, C. 578 (2003). Isometric Logratio Transformations for Compositional Data Analysis. 
579 Mathematical Geology, 35(3), 279-300. doi:10.1023/A:1023818214614

580 Fox, J. F., \& Papanicolaou, A. N. (2008). An un-mixing model to study watershed 581 erosion processes. Advances in Water Resources, 31, 96-108. $582 \quad$ doi:10.1016/j.advwatres.2007.06.008

583 Garzanti, E., Vermeesch, P., Ando, S., Vezzoli, G., Valagussa, M., Allen, K., Kadi, 584 K.A., Al-Juboury, A.I.A., 2013. Provenance and recycling of Arabian desert 585 sand. Earth-Science Reviews. 120, 1-19.

586 Garzanti, E., Vermeesch, P., Padoan, M., Resentini, A., Vezzoli, G., Ando, S., 2014. 587 Provenance of Passive-Margin Sand (Southern Africa). Journal of Geology, $588 \quad$ 122(1), 17-42. doi:10.1086/674803

589 Gellis, A. C., \& Noe, G. B. (2013). Sediment source analysis in the Linganore Creek 590 watershed, Maryland, USA, using the sediment fingerprinting approach: 2008 to 591 2010. Journal of Soils and Sediments, 13(10), 1735-1753. doi:10.1007/s11368$592 \quad$ 013-0771-6

Haddadchi, A, Ryder, D.S., Evrard, O., Olley, J. (2013). Sediment fingerprinting in 594 fluvial systems: review of tracers, sediment sources and mixing models. Int. J. $595 \quad$ Sediment Res., 28, 560-578

596 Huntsman-Mapila, P., Kampunzu, A.B., Vink, B., Ringrose, S., 2005. Cryptic 597 indicators of provenance from the geochemistry of the Okavango Delta $598 \quad$ sediments, Botswana. Sedimentary Geology 174, 123-148.

599 Honda, M., Yabuki, S., \& Shimizu, H. S. H. I. (2004). Geochemical and isotopic 600 studies of aeolian sediments in China. Sedimentology, 211-230. $601 \quad$ doi:10.1046/j.1365-3091.2003.00618.x 
602 Jia, Y., Fu, B., Jolivet, M. and Zheng, S. Cenozoic tectono-geomorphological growth 603 of the SW Chinese Tian Shan: insight from AFT and detrital zircon U-Pb data. $604 \quad$ Journal of Asian Earth Sciences, 2015, 111, 395-413.

605 Koiter, A. J., Owens, P. N., Petticrew, E. L., \& Lobb, D. A. (2013). The behavioural 606 characteristics of sediment properties and their implications for sediment 607 fingerprinting as an approach for identifying sediment sources in river basins. 608 Earth-Science Reviews, 125, 24-42. doi:10.1016/j.earscirev.2013.05.009

609 Lancaster, N. 1995.Geomorphology of Desert Dunes. Routledge, London.

610 Lin, J., Huang, Y., Wang, M. kuang, Jiang, F., Zhang, X., \& Ge, H. (2015). Assessing 611 the sources of sediment transported in gully systems using a fingerprinting 612 approach: An example from South-east China. Catena, 129, 9-17. 613 doi:10.1016/j.catena.2015.02.012

614 Liu, B.L., Niu, Q.H., Qu, J.J., Zu, R.P. (2016). Quantifying the provenance of aeolian 615 sediments using multiple composite fingerprints. Aeolian Research, 22, 117$616 \quad$ 122. doi:10.1016/j.aeolia.2016.08.002

617 Lunn, D.J., Thomas, A., Best, N., and Spiegelhalter, D. (2000) WinBUGS -- a 618 Bayesian modelling framework: concepts, structure, and extensibility. Statistics 619 and Computing, 10:325--337.

620 Martínez-Carreras, N., Udelhoven, T., Krein, A., Gallart, F., Iffly, J. F., Ziebel, J. and 621 Walling, D. E. (2010). The use of sediment colour measured by diffuse 622 reflectance spectrometry to determine sediment sources: Application to the 623 Attert River catchment. Journal of Hydrology, 382(1-4), 49-63. 624 doi:10.1016/j.jhydrol.2009.12.017 
625 Massoudieh, A., Gellis, A., Banks, W. S., \& Wieczorek, M. E. (2013). Suspended 626 sediment source apportionment in Chesapeake Bay watershed using Bayesian 627 chemical mass balance receptor modeling. Hydrological Processes, 27(24), 628 3363-3374. doi:10.1002/hyp.9429

629 Motha, J. A., Wallbrink, P. J., Hairsine, P. B., \& Grayson, R. B. (2003). Determining 630 the sources of suspended sediment in a forested catchment in southeastern 631 Australia. Water Resources Research, 39(3), 1056. doi:10.1029/2001wr000794

632 Muhs, D. R., Lancaster, N. and Skipp, G.L. (2017). A complex origin for the Kelso 633 Dunes, Mojave National Preserve, California, USA: A case study using a simple 634 geochemical method with global applications. Geomorphology, 276, 222-243. 635 doi: 10.1016/j.geomorph.2016.10.002

636 Mukundan, R., Walling, D. E., Gellis, A. C., Slattery, M. C., \& Radcliffe, D. E. (2012). 637 Sediment Source Fingerprinting: Transforming From a Research Tool to a 638 Management Tool. Journal of the American Water Resources Association, 639 48(6), 1241-1257. doi:10.1111/j.1752-1688.2012.00685.x

640 Naddafi, K., Nabizadeh, R., Soltanianzadeh, Z., Ehrampoosh, M.H., 2006. 641 Evaluation of dustfall in the air of Yazd. Journal of Environmental Health $642 \quad$ Science and Engineering, 3, 161-168.

643 Nanson, G.C., Chen, X.Y., Price, D.M. (1995). Aeolian and fluvial evidence of 644 changing climate and wind patterns during the past $100 \mathrm{Ka}$ in the Western 645 Simpson Desert, Australia. Palaeogeography Palaeoclimatology Palaeoecology $646 \quad 113,87-102$.

647 Nie, J. and Peng, W. (2014). Automated SEM-EDS heavy mineral analysis reveals 
648 no provenance shift between glacial loess and interglacial paleosol on the 649 Chinese Loess Plateau. Aeolian Research 13, 71-75.

650 Nosrati, K., Govers, G., Semmens, B. X., \& Ward, E. J. (2014). A mixing model to 651 incorporate uncertainty in sediment fingerprinting. Geoderma 217-218, 173-180. 652 653 654 655 656 doi:10.1016/j.geoderma.2013.12.002

Owens, P.N., Blake, W.H., Gaspar, L., Gateuille, D., Koiter, A.J., Lobb, D.A., Petticrew, E.L., Reiffarth, D.G., Smith, H.G. \& Woodward, J.C. (2016). Fingerprinting and tracing the sources of soils and sediments: Earth and ocean science, geoarchaeological, forensic, and human health applications. EarthScience Reviews, 162, 1-23. doi: 10.1016/j.earscirev.2016.08.012

Palmer, M. J., \& Douglas, G. B. (2008). A Bayesian statistical model for end member analysis of sediment geochemistry, incorporating spatial dependences. Journal of the Royal Statistical Society. Series C: Applied Statistics 57(3), 313-327. doi:10.1111/j.1467-9876.2007.00615.x

Parnell, A. C., Phillips, D. L., Bearhop, S., Semmens, B. X., Ward, E. J., Moore, J. W., Inger, R. (2013). Bayesian stable isotope mixing models. Environmetrics 24(6), 387-399. doi:10.1002/env.2221

Pell, S.D., Williams, I.S., Chivas, A.R., 1997. The use of protolith zircon-age fingerprints in determining the protosource areas for some Australian dune sands. Sedimentary Geology 109, 233-260.

Pell, S.D., Chivas, A.R., Williams, I.S. 2000. The Simpson, Strzelecki and Tirari Deserts: development and sand provenance. Sedimentary Geology 130 (1-2), 107-130. doi: 10.1016/S0037-0738(99)00108-6 
671 Pethierick, L., McGowan, H., Moss, P., 2008. Climate variability during the Last 672 Glacial Maximum in eastern Australia: evidence of two stadials? Journal of 673 Quaternary Science 23, 787-802.

674 Pittam, N. J., Foster, I. D. L., \& Mighall, T. M. (2009). An integrated lake-catchment 675 approach for determining sediment source changes at Aqualate Mere, Central 676 England. Journal of Paleolimnology, 42(2), 215-232. doi:10.1007/s10933-008$677 \quad 9272-9$

678 Rao, W., Tan, H., Jiang, S., \& Chen, J. (2011). Trace element and REE 679 geochemistry of fine- and coarse-grained sands in the Ordos deserts and links 680 with sediments in surrounding areas. Chemie Der Erde - Geochemistry, 71(2), 681 155-170. doi:10.1016/j.chemer.2011.02.003

682 Ren, R., Han, B-F., Xu, Z. and Li, Q. 2014. When did the subduction first initiate in 683 the southern Paleo-Asian Ocean: New constraints from a Cambrian intra684 oceanic arc system in West Junggar, NW China. Earth and Planetary Science $685 \quad$ Letters 388, 222-236

686 Semmens, B. X., Moore, J. W., \& Ward, E. J. (2009). Improving Bayesian isotope 687 mixing models: A response to Jackson et al. (2009). Ecology Letters, 12(3), 10$688 \quad$ 12. doi:10.1111/j.1461-0248.2009.01283.x

689 Sherriff, S. C., Franks, S. W., Rowan, J. S., Fenton, O., \& Ó’hUallacháin, D. (2015). 690 Uncertainty-based assessment of tracer selection, tracer non-conservativeness 691 and multiple solutions in sediment fingerprinting using synthetic and field data. 692 Journal of Soils and Sediments, 15(10), 2101-2116. doi:10.1007/s11368-015$693 \quad 1123-5$ 
694 Smith, H. G., \& Blake, W. H. (2014). Sediment fingerprinting in agricultural 695 catchments: A critical re-examination of source discrimination and data 696 697

Geomorphology,

204 ,

177-191. doi:10.1016/j.geomorph.2013.08.003

Stewart, H. A., Massoudieh, A., \& Gellis, A. (2015). Sediment source apportionment in Laurel Hill Creek, PA, using Bayesian chemical mass balance and isotope fingerprinting. Hydrological Processes, 29(11), 2545-2560. doi:10.1002/hyp.10364

Stone, M., Collins, A. L., Silins, U., Emelko, M. B., \& Zhang, Y. S. (2014). The use of composite fingerprints to quantify sediment sources in a wildfire impacted landscape, Alberta, Canada. Science of the Total Environment, 473-474, 642650. doi:10.1016/j.scitotenv.2013.12.052

Thorpe, R.I., Hickman, A.H., Davis, D.W., Mortensen, J.K. and Trendall, A.F., 1992. $\mathrm{U} / \mathrm{Pb}$ zircon geochronology of Archaean felsic units in the Marble Bar region, Pilbara Craton, Western Australia. Precambrian Research, 56, 169-189.

Vale, S. S., Fuller, I. C., Procter, J. N., Basher, L. R., \& Smith, I. E. (2016). Characterization and quantification of suspended sediment sources to the Manawatu River, New Zealand. Science of The Total Environment, 543, 171186. doi:10.1016/j.scitotenv.2015.11.003

Voli, M. T., Wegmann, K. W., Bohnenstiehl, D. R., Leithold, E., Osburn, C. L., \& Polyakov, V. 2013. Fingerprinting the sources of suspended sediment delivery to a large municipal drinking water reservoir: Falls Lake, Neuse River, North Carolina, USA. Journal of Soils and Sediments, 13(10), 1692-1707. 

doi:10.1007/s11368-013-0758-3

718

719

720

721

722

723

724

725

726

727

728

729

730

731

732

733

734

735

736

737

738

Walling, D.E., Collins, A.L., \& Stroud, R.W. 2008. Tracing suspended sediment and particulate phosphorus sources in catchments. Journal of Hydrology, 350(3-4), 274-289. doi:10.1016/j.jhydrol.2007.10.047

Walling, D.E. 2013. The evolution of sediment source fingerprinting investigations in fluvial systems. Journal of Soils and Sediments, 13(10), 1658-1675. doi: $10.1007 / \mathrm{s} 11368-013-0767-2$

Wasklewicz, T.A., Meek, N., 1995. Provenance of aeolian sediment: The upper Coachella Valley, California. Physical Geography 16, 539-556.

Wilkinson, S.N., Hancock, G.J., Bartley, R., Hawdon, A.A., \& Keen, R.J. (2013). Using sediment tracing to assess processes and spatial patterns of erosion in grazed rangelands, Burdekin River basin, Australia. Agriculture, Ecosystems and Environment, 180, 90-102. doi:10.1016/j.agee.2012.02.002

Wilson, C.G., Papanicolaou, A.N.T., \& Denn, K.D. (2012). Partitioning fine sediment loads in a headwater system with intensive agriculture. Journal of Soils and Sediments, 12(6), 966-981. doi:10.1007/s11368-012-0504-2

Winspear, N.R., Pye, K., 1996. Textural, geochemical and mineralogical evidence for the sources of aeolian sand in central and southwestern Nebraska, USA. Sedimentary Geology 101, 85-98.

Yang, X., Liu, Y., Li, C., Song, Y., Zhu, H., Jin, X., 2007. Rare earth elements of aeolian deposits in Northern China and their implications for determining the provenance of dust storms in Beijing. Geomorphology 87, 365-377. 


$\begin{array}{ll}1 & \\ 2 & \\ 3 & 739 \\ 4 & \\ 5 & \\ 6 & 740 \\ 7 & \\ 8 & \\ 9 & 741 \\ 10 & \end{array}$

10

11

12

13

14

15

16

17

18

19

20

21

22

23

24

25

26

27

28

29

30

31

32

33

34

35

36

37

38

39

40

41

42

43

44

45

46

47

48

49

50

51

52

53

54

55

56

57

58

59

60 
742 Tables

743 Table 1

\begin{tabular}{|c|c|c|c|c|c|c|c|}
\hline & & \multicolumn{6}{|c|}{ Grain size $(\mu \mathrm{m})$} \\
\hline & & $<62.5$ & $\begin{array}{l}62.5- \\
150\end{array}$ & $\begin{array}{l}150- \\
300\end{array}$ & $\begin{array}{l}300- \\
600\end{array}$ & $\begin{array}{l}600- \\
1180\end{array}$ & $\begin{array}{l}1180- \\
1700\end{array}$ \\
\hline $\begin{array}{l}\text { Mean Eocene marl (Egm) source } \\
(\% \pm 1 \sigma)\end{array}$ & & $\begin{array}{r}3.0 \pm \\
1.4\end{array}$ & $\begin{array}{r}40.2 \pm \\
10.6\end{array}$ & $\begin{array}{r}20.0 \pm \\
6\end{array}$ & $\begin{array}{r}15.1 \pm \\
4.2\end{array}$ & $\begin{array}{r}15.6 \pm \\
6.7\end{array}$ & $6.1 \pm 5$ \\
\hline $\begin{array}{l}\text { Mean Quaternary clay flat (Qc) } \\
\text { source }(\% \pm 1 \sigma)\end{array}$ & & $\begin{array}{r}3.1 \pm \\
1.3\end{array}$ & $\begin{array}{r}29.4 \pm \\
9.2\end{array}$ & $\begin{array}{r}21.8 \pm \\
5.6\end{array}$ & $\begin{array}{r}19.0 \pm \\
3.9\end{array}$ & $\begin{array}{r}19.7 \pm \\
8.1\end{array}$ & $6.9 \pm 4$ \\
\hline $\begin{array}{l}\text { Mean Quaternary terrace/fan (Qt2) } \\
\text { source }(\% \pm 1 \sigma)\end{array}$ & & $\begin{array}{r}2.2 \pm \\
2.3\end{array}$ & $\begin{array}{r}34.7 \pm \\
7.3\end{array}$ & $\begin{array}{r}20.4 \pm \\
5.6\end{array}$ & $\begin{array}{r}17.1 \pm \\
3.9\end{array}$ & $\begin{array}{r}19.3 \pm \\
5.3\end{array}$ & $6.4 \pm 2$ \\
\hline $\begin{array}{l}\text { Mean Ashkzar erg dune sands (\% } \pm \\
1 \sigma)\end{array}$ & & $\begin{array}{r}1.1 \pm \\
0.9\end{array}$ & $\begin{array}{r}47.8 \pm \\
9.3\end{array}$ & $\begin{array}{r}29.7 \pm \\
8.4\end{array}$ & $\begin{array}{r}17.4 \pm \\
13.9\end{array}$ & $\begin{array}{r}3.4 \pm \\
5.4\end{array}$ & $0.6 \pm 1.3$ \\
\hline Ashkzar erg dune samples (\%) & A & 0.3 & 57.6 & 38.2 & 3.4 & 0.5 & 0.0 \\
\hline & B & 0.5 & 41.0 & 18.1 & 39.0 & 1.4 & 0.0 \\
\hline & C & 2.1 & 43.9 & 16.7 & 35.9 & 1.4 & 0.0 \\
\hline & $\mathrm{D}$ & 0.5 & 42.5 & 34.0 & 22.0 & 1.0 & 0.0 \\
\hline & $E$ & 2.7 & 51.8 & 31.2 & 7.9 & 5.0 & 1.4 \\
\hline & $\mathrm{F}$ & 1.0 & 64.5 & 32.0 & 2.5 & 0.0 & 0.0 \\
\hline & G & 1.0 & 36.8 & 28.0 & 14.4 & 16.2 & 3.6 \\
\hline & $\mathrm{H}$ & 0.6 & 44.6 & 39.3 & 13.7 & 1.8 & 0.0 \\
\hline
\end{tabular}


745 Table 2 

\begin{tabular}{|c|c|c|c|c|c|}
\hline $\begin{array}{l}\text { Fingerprint } \\
\text { property }\end{array}$ & Chi square & $p$ value & Fingerprint property & Chi square & $p$-value \\
\hline $\mathrm{La}$ & 6.669 & 0.036 & $\mathrm{Y}$ & 4.151 & 0.125 \\
\hline $\mathrm{Ce}$ & 7.476 & $0.024^{\star}$ & $\mathrm{Zr}$ & 3.744 & 0.154 \\
\hline $\mathrm{Pr}$ & 9.552 & $0.008^{* \pi}$ & $\mathrm{Nb}$ & 0.582 & 0.748 \\
\hline $\mathrm{Nd}$ & 0.415 & 0.813 & $\mathrm{Hf}$ & 16.1 & $<0.001^{* *}$ \\
\hline $\mathrm{Sm}$ & 0.081 & 0.96 & $\mathrm{Ta}$ & 4.922 & 0.085 \\
\hline $\mathrm{Eu}$ & 10.23 & $0.006^{\pi \pi}$ & Th & 10.28 & $0.006^{\pi \pi}$ \\
\hline $\mathrm{Gd}$ & 0.434 & 0.805 & U & 4.8 & 0.091 \\
\hline $\mathrm{Tb}$ & 0.017 & 0.992 & As & 5.166 & 0.076 \\
\hline Dy & 1.359 & 0.507 & $\mathrm{Bi}$ & 0.725 & 0.695 \\
\hline $\mathrm{Ho}$ & 8.067 & $0.018^{\star}$ & $\mathrm{Cd}$ & 0.111 & 0.946 \\
\hline $\mathrm{Er}$ & 9.257 & $0.01^{\pi}$ & $\mathrm{Ga}$ & 13.4 & $<0.001^{20}$ \\
\hline $\mathrm{Tm}$ & 8.373 & $0.015^{\star}$ & $\mathrm{Ge}$ & 0.59 & 0.745 \\
\hline $\mathrm{Yb}$ & 1.026 & 0.599 & In & 1.215 & 0.545 \\
\hline $\mathrm{Lu}$ & 0.104 & 0.949 & $\mathrm{Li}$ & 7.213 & $0.027^{\star}$ \\
\hline$\sum$ REE & 7.086 & $0.029^{\star}$ & Mo & 0.227 & 0.893 \\
\hline $\mathrm{Eu} / \mathrm{Eu}^{*}$ & 10.23 & $0.006^{\pi \pi}$ & $\mathrm{P}$ & 13.05 & $<0.001_{m x}^{m \times}$ \\
\hline$(\mathrm{Nd} / \mathrm{Yb})$ & 0.785 & 0.675 & S & 16.36 & $<0.001^{* *}$ \\
\hline$(\mathrm{Gd} / \mathrm{Yb})_{\mathrm{n}}$ & 0.729 & 0.695 & $\mathrm{Sb}$ & 1.409 & 0.494 \\
\hline$(\mathrm{La} / \mathrm{Yb})_{\mathrm{n}}$ & 13.89 & $0.001^{\star \pi x}$ & $\mathrm{Se}$ & 0.858 & 0.651 \\
\hline$(\mathrm{La} / \mathrm{Sm})_{\mathrm{n}}$ & 4.725 & 0.094 & Sn & 6.466 & $0.039^{\star}$ \\
\hline$(\mathrm{La} / \mathrm{Lu})_{\mathrm{n}}$ & 12.78 & $0.002^{\pi x}$ & $\mathrm{Te}$ & 4.685 & 0.096 \\
\hline$\delta \mathrm{Ce}$ & 5.435 & $0.041^{*}$ & $\mathrm{Ti}$ & 6.56 & $0.038^{*}$ \\
\hline $\mathrm{Rb}$ & 15.18 & $<0.001^{\infty x}$ & $\mathrm{TI}$ & 6.614 & $0.037^{\star}$ \\
\hline $\mathrm{Sr}$ & 16.44 & $<0.001^{m-1}$ & W & 0.086 & 0.958 \\
\hline $\mathrm{Ba}$ & 6.379 & $0.041^{\circ}$ & $\mathrm{Mn}$ & 1.673 & 0.433 \\
\hline $\mathrm{V}$ & 3.083 & 0.214 & $\mathrm{Si}$ & 0.342 & 0.843 \\
\hline $\mathrm{Cr}$ & 5.359 & 0.069 & ${ }^{143} \mathrm{Nd}$ & 1.042 & 0.534 \\
\hline Co & 1.271 & 0.53 & ${ }^{144} \mathrm{Nd}$ & 2.031 & 0.362 \\
\hline $\mathrm{Ni}$ & 3.998 & 0.135 & ${ }^{86} \mathrm{Sr}$ & 5.754 & 0.056 \\
\hline $\mathrm{Cu}$ & 3.18 & 0.204 & ${ }^{87} \mathrm{Sr}$ & 7.124 & $0.028^{*}$ \\
\hline $\mathrm{Zn}$ & 0.236 & 0.889 & & & \\
\hline
\end{tabular}


Table 3

\begin{tabular}{cccccccc}
\hline \multirow{2}{*}{ Sediment } & Tracer & $\mathrm{Rb}$ & $\mathrm{Sr}$ & ${ }^{8 /} \mathrm{Sr}$ & $(\mathrm{La} / \mathrm{Yb})_{\mathrm{n}}$ & $\mathrm{Ga}$ & $\delta \mathrm{Ce}$ \\
\hline \multirow{nyyyyyy}{\text{Sanddune}}{} & Mean & 7.8 & 144 & 85 & 7.1 & 1.2 & 0.69 \\
& $\mathrm{SD}$ & 0.74 & 18.6 & 28 & 0.54 & 0.11 & 0.020 \\
\hline Source & Tracer & $\mathrm{Rb}$ & $\mathrm{Sr}$ & ${ }^{8 /} \mathrm{Sr}$ & $(\mathrm{La} / \mathrm{Yb})_{\mathrm{n}}$ & $\mathrm{Ga}$ & $\delta \mathrm{Ce}$ \\
\hline Egm & Mean & 8.9 & 293 & 82 & 6.9 & 1.3 & 0.70 \\
& $\mathrm{SD}$ & 2.3 & 192 & 31 & 0.58 & 0.29 & 0.085 \\
Qc & Mean & 10 & 139 & 91 & 7.4 & 1.1 & 0.69 \\
& SD & 2.6 & 36.5 & 31 & 0.54 & 0.27 & 0.071 \\
Qt2 & Mean & 7.1 & 163 & 98 & 7.7 & 0.99 & 0.74 \\
& SD & 0.82 & 135 & 44 & 0.89 & 0.26 & 0.27 \\
\hline
\end{tabular}

748

749 Table 4

Tracer

\begin{tabular}{|c|c|c|c|c|c|c|c|}
\hline & Source & $\mathrm{Rb}$ & $\mathrm{Sr}$ & ${ }^{87} \mathrm{Sr}$ & (La/Yb)n & $\mathrm{Ga}$ & $\delta \mathrm{Ce}$ \\
\hline \multirow{5}{*}{$\begin{array}{l}\frac{\pi}{\pi} \\
\frac{\pi}{0} \\
3 \\
\mathbb{\pi} \\
\square\end{array}$} & Egm & 0.944 & 0.362 & 0.930 & 0.996 & 0.980 & 0.810 \\
\hline & Qc & 0.347 & 0.734 & 0.486 & 0.794 & 0.900 & 0.167 \\
\hline & Qt2 & 0.983 & 0.019 & 0.182 & 0.557 & 0.710 & 0.013 \\
\hline & & & & & cer & & \\
\hline & Source & $\mathrm{Rb}$ & $\mathrm{Sr}$ & ${ }^{87} \mathrm{Sr}$ & $(\mathrm{La} / \mathrm{Yb}) \mathrm{n}$ & $\mathrm{Ga}$ & $\delta \mathrm{Ce}$ \\
\hline \multirow{3}{*}{ 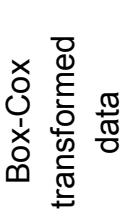 } & Egm & 0.944 & 0.724 & 0.930 & 0.996 & 0.980 & 0.978 \\
\hline & Qc & 0.347 & 0.931 & 0.486 & 0.794 & 0.900 & 0.542 \\
\hline & Qt2 & 0.983 & 0.085 & 0.182 & 0.557 & 0.710 & 0.061 \\
\hline
\end{tabular}

750

$751 \quad$ Table 5

752

\begin{tabular}{cccccccc}
\hline $\begin{array}{c}\text { Sediment } \\
\text { samples }\end{array}$ & Source & $\begin{array}{c}\text { Mean } \\
(\%)\end{array}$ & $\begin{array}{c}\text { SD } \\
(\%)\end{array}$ & $\begin{array}{c}\text { MC } \\
\text { error }\end{array}$ & Median & $\begin{array}{c}\text { Percentile } \\
(2.5)\end{array}$ & $\begin{array}{c}\text { Percentile } \\
(97.5)\end{array}$ \\
\hline \multirow{2}{*}{$\mathrm{A}$} & Egm & 44.1 & 11.5 & 0.003 & 44.5 & 21 & 64.7 \\
& Qc & 39.8 & 11.2 & 0.003 & 37.9 & 22.7 & 65.8 \\
& Qt2 & 16.2 & 8.3 & 0.001 & 15.2 & 3.6 & 34 \\
B & Egm & 32.6 & 7.3 & 0.002 & 33 & 18.2 & 46.2 \\
& Qc & 5.1 & 3.8 & 0.001 & 4.1 & 0.6 & 15 \\
& Qt2 & 62.2 & 6 & 0.001 & 62.1 & 50.3 & 73.7 \\
C & Egm & 20.8 & 6.3 & 0.002 & 21 & 8.1 & 33 \\
& Qc & 27.5 & 6.5 & 0.002 & 26.6 & 17.1 & 43 \\
& Qt2 & 51.6 & 5.2 & 0.000 & 51.1 & 42 & 62.5 \\
D & Egm & 56.3 & 13 & 0.004 & 56.9 & 29.9 & 79.4 \\
& Qc & 28.7 & 10.5 & 0.003 & 27 & 12.2 & 53.4 \\
& Qt2 & 14.9 & 9.4 & 0.001 & 14.4 & 0.4 & 34.2 \\
E & Egm & 14.3 & 5 & 0.001 & 14.3 & 4.6 & 24.6
\end{tabular}




\begin{tabular}{cccccccc} 
& Qc & 23 & 5.3 & 0.001 & 22.3 & 14.2 & 35.1 \\
& Qt2 & 62.6 & 4.8 & 0.000 & 62.7 & 52 & 71.9 \\
$\mathrm{~F}$ & Egm & 17.6 & 6.3 & 0.001 & 17.7 & 4.8 & 29.9 \\
& Qc & 32.4 & 7.4 & 0.002 & 31.5 & 20.4 & 49.6 \\
& Qt2 & 49.9 & 5.5 & 0.001 & 49.4 & 39.7 & 61.5 \\
$\mathrm{G}$ & Egm & 3.4 & 3.2 & 0.000 & 2.44 & 0.000 & 12.2 \\
& Qc & 3.9 & 3.9 & 0.000 & 2.6 & 0.000 & 14.7 \\
& Qt2 & 92.7 & 6 & 0.001 & 94 & 78.2 & 99.7 \\
\hline $\mathrm{H}$ & Egm & 37.3 & 11.2 & 0.003 & 37.8 & 14.5 & 57.9 \\
& Qc & 49.7 & 12.6 & 0.004 & 47.7 & 30 & 79 \\
& Qt2 & 13 & 8.6 & 0.001 & 12 & 0.4 & 31.5
\end{tabular}

753

754 
755 Figure captions

756

757 Figure 1: Location and geological map of the Yazd-Ardekan Plain and sampling 758 sites. Dominant and minor wind directions shown in Part C. Number of sampling 759 points $=57$. Qt2, Qc, Egm (potential sediment sources) and Qsd (sediment) 760 represent young alluvial fans and terraces, clay flats, gypsiferous marl and sand 761 dunes, respectively.

Figure 2: Source and sediment sink regions within the study area. Source regions 764 include: a) clay flats (Qc); b) gypsiferous marl (Egm); and c) young alluvial fans and terraces (Qt2). Sediment sinks include: d) sand dunes (Qsd).

766

767

Figure 3. Morphological mapping of dune types within Ashkzar erg reveals the 768 dominance of barchans and barchanoid ridges. There are less distinct zones within the dunefield in the north, where the interdunes are sandy and the transverse forms much less distinct, and in the far southeast, where patchy slipface-less dunes dominate. Base imagery is courtesy of Google Earth ${ }^{\mathrm{TM}}$, and letters refer to the eight samples analysed for physical and geochemical characteristics within the dunefield.

Figure 4: A directed acyclic graph of the Bayesian mixing model employed in this study.

Figure 5: Two-dimensional scatter plot of the first and second discriminant functions 778 from stepwise DFA for the source groups Egm (Eocene gypsiferous marls), Qc 779 (Quaternary clay flats) and Qt2 (Quaternary alluvial fans and terraces). 
780 Figure 6: Source contributions for each aeolian sediment samples by Bayesian 781 mixing model with 95\% credible limits. Base imagery is courtesy of Google Earth ${ }^{\mathrm{TM}}$.

782

783 Table captions

784 Table 1: Grain size data for the source areas, the dunefield, and individual samples 785 from within the dunefield.

786

787

Table 2: Kruskal-Wallis $H$ test results for selecting fingerprint properties for 788 distinguishing individual source types. Confidence is highlighted at $>95 \%$ with a 789 single asterisk, $>99 \%$ with a double asterisk, and $>99.9 \%$ with a triple asterisk. 790

791 Table 3: Summary geochemistry data for sand dune samples and potential sediment 792 sources. All are reported to two significant figures, except Sr, which is reported to 793 three, due to the larger magnitude of the concentrations.

Table 4: Normality tests on the raw data for the tracers selected for the fingerprint 796 revealed that two tracers $(\mathrm{Sr}$ and $\delta \mathrm{Ce})$ were not normally distributed for the Qt2 unit; 797 for this reason, Box-Cox transformations were performed on all data, which did 798 provide normal distributions for all tracers.

799

800 Table 5. Estimated contribution from each source for aeolian sediment samples by 801 Bayesian mixing model. 

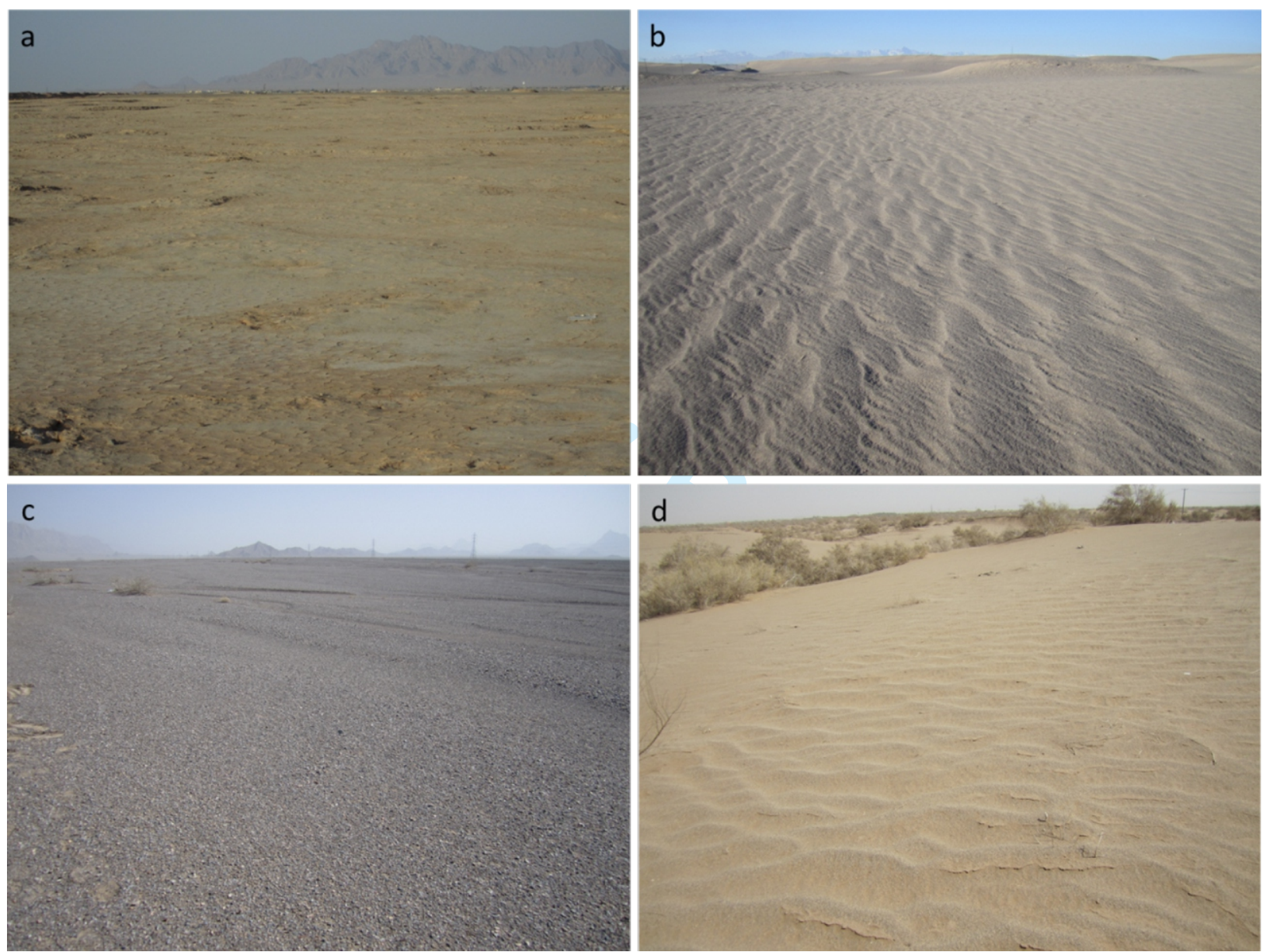

http://mc.manuscriptcentral.com/esp 


\section{Earth Surface Processes and Landforms}

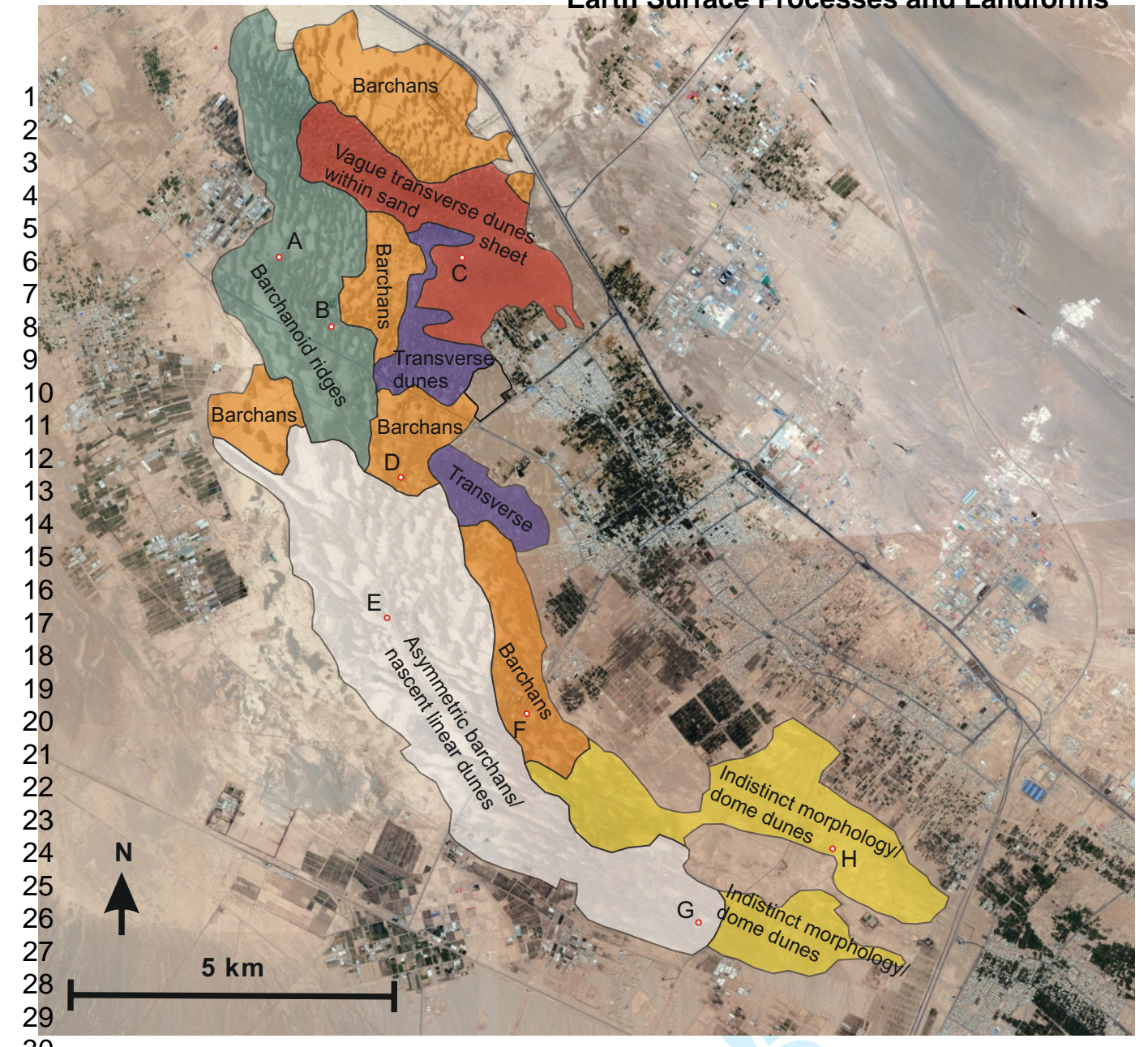




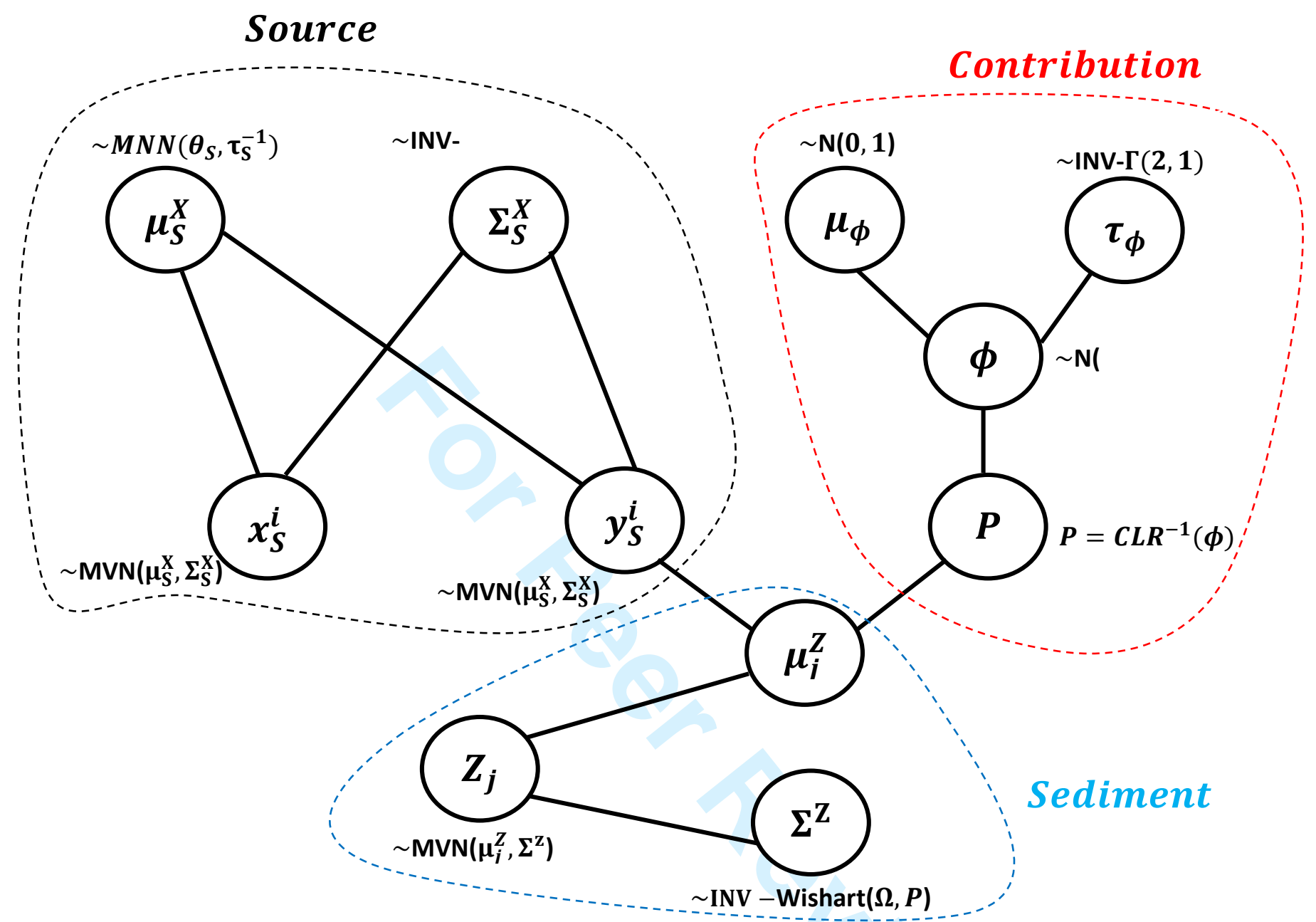




\section{Earth Surface Processes and Landforms Page 44 of 45}

1
2
3
4
5
6
7
8
9

10

11

12

13

14

15

16

17

18

19

20

21

22

23

24

http://mc.manuscriptcentral.com/esp

O Egm

$\square \mathrm{QC}$

$\Delta$ Qt2

$\nabla$ Group Centroid<smiles>[O-][18O]</smiles>

$\square \quad \square^{\square} \stackrel{0}{\Delta}{ }^{\Delta} \Delta^{q}{ }_{\Delta}$

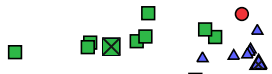

$\square \quad \square \quad \square \Delta \Delta_{\Delta}^{\Delta \Delta} \Delta_{\Delta}^{\Delta}$

$\square$

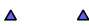

$\triangle$

Function 1

25

26 
